\title{
Thermodynamic properties and microstructural characteristics of binary Ag-Sn alloys
}

\author{
ZHAI Wei \& WEI BingBo* \\ Key Laboratory of Space Applied Physics and Chemistry, Ministry of Education, Northwestern Polytechnical University, Xi'an 710072, China
}

Received December 20, 2012; accepted January 6, 2013

\begin{abstract}
The liquidus and solidus temperatures and enthalpy of fusion for Ag-Sn alloys are systematically measured within the whole composition range by differential scanning calorimetry (DSC). The measured enthalpy of fusion is related to Sn content by polynomial functions, which exhibit one maximum value at $52 \mathrm{wt} \% \mathrm{Sn}$ and two minimum values around $21 \mathrm{wt} \% \mathrm{Sn}$ and $96.5 \mathrm{wt} \% \mathrm{Sn}$, respectively. The liquidus slope, the solidification temperature interval, the solute partition coefficient and the entropy of fusion are calculated on the basis of the measured results. The undercoolability of those liquid Ag-Sn alloys solidifying with primary (Ag) solid solution phase is stronger than the other alloys with the preferential nucleation of $\zeta$ and $\varepsilon$ intermetallic compounds. Morphological observations reveal that peritectic reactions can rarely be completed, and the peritectic microstructures are always composed of both primary and peritectic phases.
\end{abstract}

Ag-Sn alloy, enthalpy of fusion, undercoolability, peritectic solidification

Citation: Zhai W, Wei B B. Thermodynamic properties and microstructural characteristics of binary Ag-Sn alloys. Chin Sci Bull, 2013, 58: 938-944, doi: $10.1007 / \mathrm{s} 11434-013-5695-4$

In recent years, Ag-Sn alloys have aroused great scientific research interest because the $\mathrm{Ag}$ rich $\mathrm{Ag}$-Sn alloys show excellent electronic conductivity and the Sn-rich Sn-Ag alloys are idea substitutes for lead-free solders [1-5]. Many investigations reveal that the thermodynamic properties of liquid alloys and the final solid microstructures affect their performance [6-13]. However, there are few reports on these subjects for Ag-Sn alloys, and therefore, efforts should be made to the thermal properties and solidification microstructures of different Ag-Sn alloys in order to explore and understand their physical properties.

The present work focuses on the following three aspects. Firstly, the liquidus temperature and enthalpy of fusion for Ag-Sn alloys are fundamental thermodynamic parameters in determining other thermal properties. Although the enthalpy of fusion for binary alloys can be roughly estimated by Neumann-Kopp's rule from the values of the two pure components, this method usually brings in large discrepancy. Hence, the enthalpy of fusion for Ag-Sn alloys versus

*Corresponding author (email: bbwei@nwpu.edu.cn) composition should be measured experimentally. Secondly, the solidification microstructure is mainly undercoolingdependent, and hence, much work has been done to prevent the heterogeneous nucleation of liquid alloys by various denucleation techniques. One may neglect the fact that the undercoolability of liquid alloys also relies on the alloy composition, and different alloys may be undercooled by varying degrees even under the same external condition. From this point of view, it is essential to study the intrinsic undercoolability of binary $\mathrm{Ag}-\mathrm{Sn}$ alloys with different compositions. Thirdly, for Ag-Sn alloys, there are two peritectic reactions and one eutectic transformation in the binary phase diagram. However, the growth morphologies of Ag-Sn peritectic and eutectic alloys are not well known and should be investigated.

The differential scanning calorimetry (DSC) is an efficient technique for quantitative thermal properties [14,15], which also provides the essential information on the liquid to solid phase transition characteristics [16]. In present work, the enthalpy of fusion for Ag-Sn alloys within the entire composition range is measured by DSC method. The un- 
dercoolability of liquid Ag-Sn alloys with different compositions is also studied. Meanwhile, the thermal characteristics and the final solidification microstructures of typical peritectic and eutectic Ag-Sn alloys are investigated on the basis of DSC calorimetric analyses.

\section{Experimental procedure}

Nineteen Ag-Sn alloys with different compositions were investigated, which are listed in Table 1 and illustrated in the binary Ag-Sn phase diagram [17] shown in Figure 1. Each sample had a mass of about $150 \mathrm{mg}$ and was prepared

Table 1 Thermodynamic properties of Ag-Sn alloys measured by DSC method

\begin{tabular}{lccc}
\hline $\begin{array}{c}\text { Alloy } \\
\text { composition }\end{array}$ & $\begin{array}{c}\text { Liquidus } \\
\text { temperature } \\
T_{\mathrm{L}}(\mathrm{K})\end{array}$ & $\begin{array}{c}\text { Fusion enthalpy } \\
\Delta H_{f}\left(\mathrm{~kJ} \mathrm{~mol}^{-1}\right)\end{array}$ & $\begin{array}{c}\text { Fusion entropy } \\
\Delta S_{f}\left(\mathrm{~J} \mathrm{~mol}^{-1} \mathrm{~K}^{-1}\right)\end{array}$ \\
\hline Ag-2.5\%Sn & 1223 & 8.81352 & 7.20648 \\
Ag-5\%Sn & 1205 & 8.14955 & 6.76312 \\
Ag-10\%Sn & 1153 & 7.58853 & 6.58155 \\
Ag-14.2\%Sn & 1107 & 7.09429 & 6.40857 \\
Ag-21\%Sn & 997 & 6.22016 & 6.23887 \\
Ag-23\%Sn & 976 & 6.31741 & 6.45952 \\
Ag-25\%Sn & 960 & 6.48410 & 6.75427 \\
Ag-27\%Sn & 934 & 6.59270 & 7.05857 \\
Ag-32\%Sn & 888 & 7.75715 & 8.73553 \\
Ag-37\%Sn & 841 & 8.30077 & 9.87011 \\
Ag-42\%Sn & 807 & 8.78680 & 10.88823 \\
Ag-47\%Sn & 781 & 9.23046 & 11.81877 \\
Ag-52\%Sn & 756 & 9.53129 & 12.60753 \\
Ag-60\%Sn & 726 & 8.84006 & 12.17640 \\
Ag-65\%Sn & 700 & 8.57640 & 12.25200 \\
Ag-75\%Sn & 663 & 7.91837 & 11.94324 \\
Ag-80\%Sn & 630 & 7.60435 & 12.07039 \\
Ag-90\%Sn & 573 & 7.03490 & 12.27731 \\
Ag-96.5\%Sn & 494 & 6.83622 & 13.83849 \\
\hline & & & \\
\hline
\end{tabular}

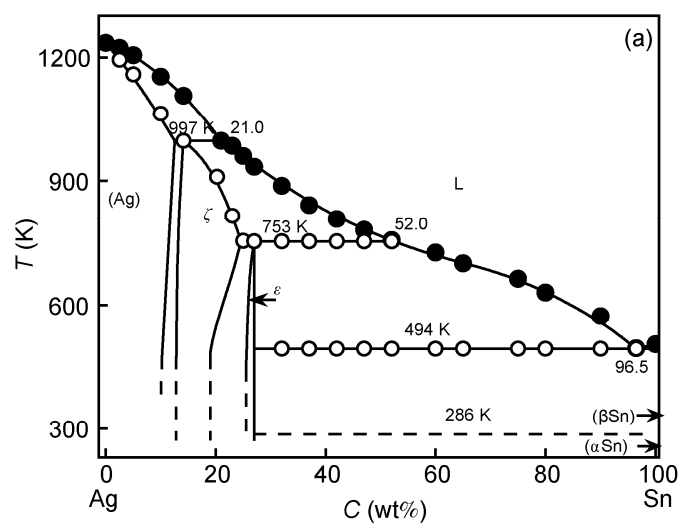

from high purity elements of $\mathrm{Ag}(99.999 \%)$ and $\mathrm{Sn}$ $(99.999 \%)$ by laser melting under the protection of argon gas. The DSC experiments were carried out with a Netzsch DSC 404C differential scanning calorimeter. The calorimeter was calibrated with the melting points and the enthalpy of fusion for high purity In, Sn, Zn, Al, Ag, Au and Fe elements. The measuring accuracies of temperature and fusion of enthalpy are $\pm 1 \mathrm{~K}$ and $\pm 3 \%$ respectively, as verified by the measurements with pure $\mathrm{Ag}$ and $\mathrm{Sn}$ elements. Before each DSC experiment, the alloy specimen was placed in an $\mathrm{Al}_{2} \mathrm{O}_{3}$ crucible. The chamber was evacuated and then backfilled with pure argon gas. The DSC thermal analyses were performed at different scan rates of 5 and $40 \mathrm{~K} / \mathrm{min}$, and the maximum heating temperatures were $100 \mathrm{~K}$ higher than the liquidus temperatures. Each specimen was heated, isothermally held at predetermined temperature, and then cooled at given scan rate for 2-3 cycles while kept in the DSC calorimeter, and the DSC profiles obtained in the last cycle was applied for further analyses. After the DSC experiments, the alloy specimens were polished and etched with a solution of $5 \mathrm{~g} \mathrm{FeCl}_{3}+1 \mathrm{~mL} \mathrm{HCl}+99 \mathrm{~mL} \mathrm{H}_{2} \mathrm{O}$, and were analyzed with an optical microscope.

\section{Results and discussion}

\subsection{Liquidus and solidus temperatures, solidification temperature interval and solute partition coefficient}

The measured liquidus temperatures of the selected alloys are marked in the Ag-Sn phase diagram shown in Figure 1(a) and listed in Table 1. Clearly, all the measured values agree well with the published phase diagram [17], which verifies the accuracy of DSC measurement. The relationship between measured liquidus temperature $T_{\mathrm{L}}$ and the $\mathrm{Sn}$ content $C$ can be well fitted by the following three functions. If the Sn content ranges from $0-21 \mathrm{wt} \%$, where the $(\mathrm{Ag})$ phase is the primary solid phase,

$$
T_{\mathrm{L}}=1236-4.93 C-0.307 C^{2} \text {. }
$$

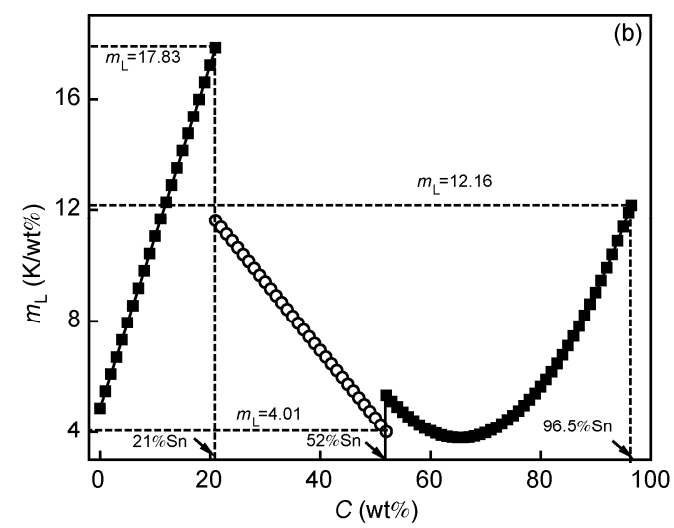

Figure 1 Selected compositions and measured results of Ag-Sn alloys. (a) Measured liquidus and solidus temperatures of selected alloys illustrated in the Ag-Sn phase diagram; (b) liquidus slope versus Sn content. 
In the Sn content range from $21 \mathrm{wt} \%$ to $52 \mathrm{wt} \%$, in which the intermetallic compound $\zeta$ phase solidifies preferentially from the alloy melt,

$$
T_{\mathrm{L}}=1314-17.54 C+0.131 C^{2} .
$$

Once the Sn content increases from 52wt $\%$ to $96.5 \mathrm{wt} \%$, where the intermetallic compound $\varepsilon$ phase is the primary solid phase:

$$
T_{\mathrm{L}}=1731-39.77 C+0.551 C^{2}-2.81 \times 10^{-3} C^{3} .
$$

Based on eqs. (1)-(3), the liquidus slope, defined as $m_{\mathrm{L}}=$ $-\mathrm{d} T_{\mathrm{L}} / \mathrm{d} C$ can be calculated. If the $\mathrm{Sn}$ content ranges from 0 to $21 \mathrm{wt} \%$, the liquidus slope rises from 4.855 to 17.83 $\mathrm{K} / \mathrm{wt} \%$ :

$$
m_{\mathrm{L}}=4.93+0.614 C .
$$

In the Sn content range from $21 \mathrm{wt} \%$ to $52 \mathrm{wt} \%$, the slope decreases from 11.605 to $4.01 \mathrm{~K} / \mathrm{wt} \%$ :

$$
m_{\mathrm{L}}=17.54-0.262 C \text {. }
$$

When the Sn content elevates from $52 \mathrm{wt} \%$ to $96.5 \mathrm{wt} \%$, it goes up from 5.33 to $12.16 \mathrm{~K} / \mathrm{wt} \%$ :

$$
m_{\mathrm{L}}=39.77-1.102 C+8.43 \times 10^{-3} C^{2} .
$$

The solidus temperatures $T_{\mathrm{S}}$ can also be obtained by the DSC experiments, which are marked in Figure 2(a) by the hollow circles. On the basis of these measured liquidus and solidus temperatures, the solidification temperature interval $\Delta T_{0}$ of $(\mathrm{Ag}), \zeta$ and $\varepsilon$ phases is calculated, and the relationship between solidification temperature interval and alloy composition is plotted in Figure 2(a). If the Sn content is in the range from 0 to $14.12 \mathrm{wt} \%$, the solidification temperature interval for $(\mathrm{Ag})$ phase is

$$
\Delta T_{0}=0.40251+10.96968 C-0.22344 C^{2} .
$$

Once the Sn content rises from to $23 \mathrm{wt} \%$ to $52 \mathrm{wt} \%$, the solidification temperature interval for $\zeta$ phase versus composition is

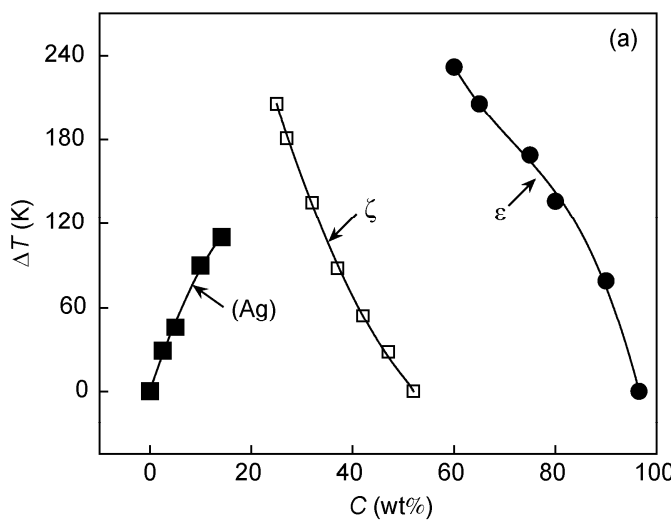

$$
\Delta T_{0}=564.96627-17.73493 C+0.13275 C^{2} .
$$

Finally, if the $\mathrm{Sn}$ content locates between $52 \mathrm{wt} \%$ and $96.5 \mathrm{wt} \%$, the solidification temperature interval for $\varepsilon$ phase can be written as:

$\Delta T_{0}=2492.29239-88.71705 C+1.17811 C^{2}-5.45 \times 10^{-3} C^{3}$. (9)

Furthermore, the solute content $C_{\mathrm{L}}$ at liquidus temperature and $C_{\mathrm{s}}$ at solidus temperature for $(\mathrm{Ag}), \zeta$ and $\varepsilon$ phases can be expressed by two functions, $C_{\mathrm{L}}=\Phi_{1}\left(T_{\mathrm{L}}\right)$ and $C_{\mathrm{s}}=$ $\Phi_{2}\left(T_{\mathrm{s}}\right)$, respectively. Thus, the variation of solute partition coefficient $k_{\mathrm{e}}=C_{\mathrm{s}} / C_{\mathrm{L}}$ with temperature for each phase can be derived. As illustrated in Figure 3(b), in the Sn content range from 0 to $21 \mathrm{wt} \%$, the solute partition coefficient for (Ag) phase is

$k_{\mathrm{e}}=-212737.30422+1168.29219 C-2.67104 C^{2}+3.25 \times 10^{-3} C^{3}$

$$
-2.22824 \times 10^{-6} C^{4}+8.13053 \times 10^{-10} C^{5}-1.2351 \times 10^{-13} C^{6} \text {. (10) }
$$

When the composition is between $21 \mathrm{wt} \%$ and $52 \mathrm{wt} \% \mathrm{Sn}$, the solute partition coefficient of $\zeta$ phase is

$$
\begin{aligned}
k_{\mathrm{e}}= & 15.50166-5.985 \times 10^{-2} C+7.7419 \times 10^{-5} C^{2} \\
& -3.24246 \times 10^{-8} C^{3} .
\end{aligned}
$$

If the $\mathrm{Sn}$ content is larger than $52 \mathrm{wt} \%$, the solute distribution of $\varepsilon$ phase is

$$
\begin{aligned}
k_{\mathrm{e}}= & -1.58652+1.036 \times 10^{-2} C-1.9597 \times 10^{-5} C^{2} \\
& +1.26733 \times 10^{-8} C^{3} .
\end{aligned}
$$

\subsection{Enthalpy and entropy of fusion}

The enthalpy of fusion for Ag-Sn alloys versus Sn content in the whole composition range, covering all the heat absorption from solidus line to liquidus temperature, is determined by the solid-liquid transformation peaks during melting process at a scan rate of $5 \mathrm{~K} / \mathrm{min}$, as summarized in Table 1. According to Figures 1(a) and 3(a), the correlation

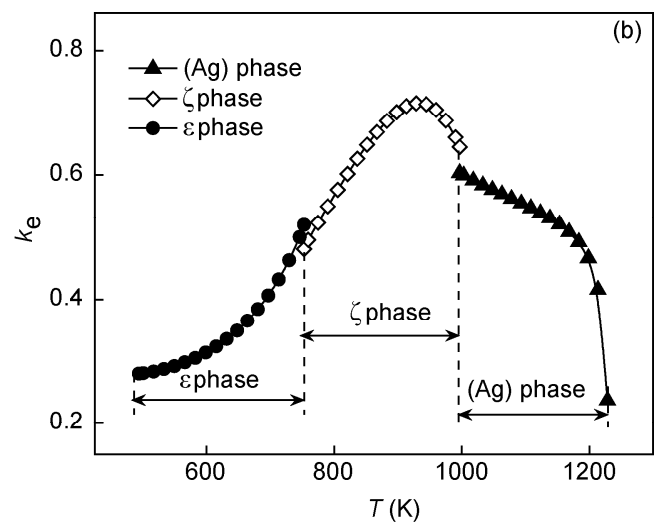

Figure 2 Solidification temperature interval and solute partition coefficient of Ag-Sn alloys. (a) Measured solidification temperature interval; (b) solute partition coefficient for $(\mathrm{Ag}), \zeta$ and $\varepsilon$ phases versus temperature. 

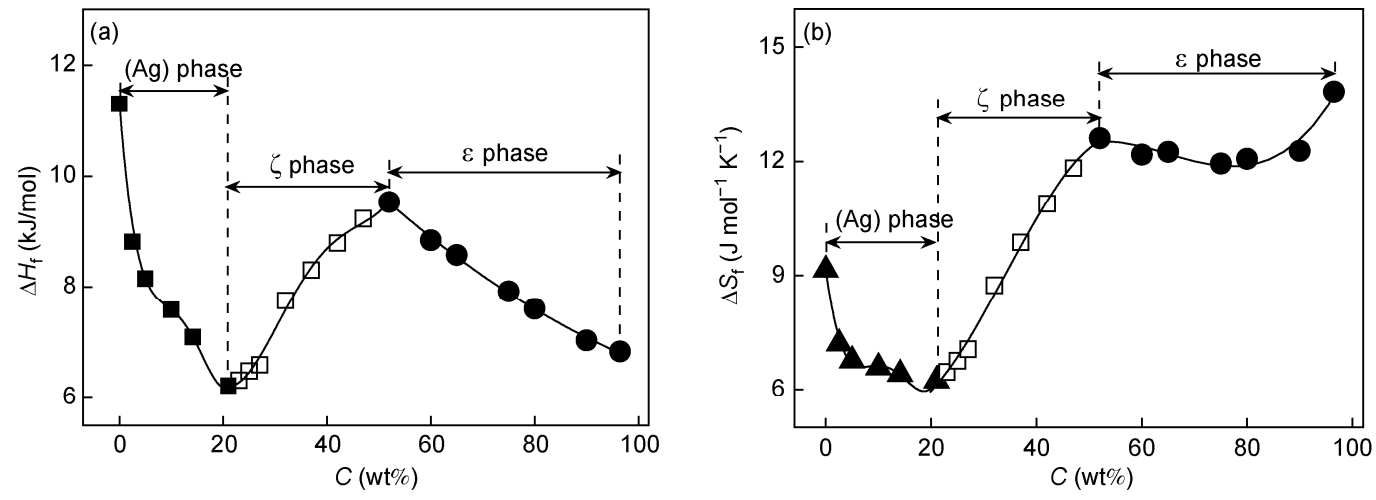

Figure 3 Measured enthalpy and entropy of fusion for Ag-Sn alloys versus Sn content. (a) Enthalpy of fusion; (b) entropy of fusion.

between enthalpy of fusion and composition is found to be closely related to the primary solid phase during the solidification of liquid $\mathrm{Ag}-\mathrm{Sn}$ alloys. In the $\mathrm{Sn}$ content range from 0 to $21 \mathrm{wt} \%$, the $(\mathrm{Ag})$ phase is the corresponding primary solid phase, and the enthalpy of fusion of $\mathrm{Ag}-\mathrm{Sn}$ alloys in this range decreases monotonically with increasing Sn content:

$$
\begin{aligned}
\Delta H_{f}= & 11.3-1.20119 C+0.154343 C^{2}-8.92 \times 10^{-3} C^{3} \\
& +1.78134 C^{4}
\end{aligned}
$$

When Sn content is in the range of $21 \mathrm{wt} \%-52 \mathrm{wt} \%$, the intermetallic compound $\zeta$ phase solidifies preferentially from the liquid alloys. In this region, the enthalpy of fusion rises with the increase of Sn content and reaches a maximum value around $52 \mathrm{wt} \%$. The relationship between enthalpy of fusion and the Sn content can be written as:

$$
\begin{aligned}
\Delta H_{f}= & 29.88249-3.0211 C+0.13449 C^{2}-2.44 \times 10^{-3} C^{3} \\
& +1.59593 \times 10^{-5} C^{4} .
\end{aligned}
$$

As for the composition range from $52 \mathrm{wt} \%$ to $96.5 \mathrm{wt} \%$ $\mathrm{Sn}$, the intermetallic compound $\varepsilon$ phase precipitates primarily from the alloy melt, and the enthalpy of fusion experiences monotonically decreasing with the increase of $\mathrm{Sn}$ content till $96.5 \mathrm{wt} \%$, which can be expressed as:

$$
\Delta H_{f}=14.96711-0.12845 C+4.54699 \times 10^{-4} C^{2} .
$$

The entropy of fusion for Ag-Sn alloys $\Delta S_{f}$ can also be calculated directly from the measured enthalpy and liquidus temperature by:

$$
\Delta S_{f}=\Delta H_{f} / T_{\mathrm{L}}
$$

The calculated results on entropy of fusion versus composition are also presented in Table 1 and shown in Figure 2(b). In the Sn range from 0 to $21 \mathrm{wt} \%$, the entropy of fusion decreases with the increase of $\mathrm{Sn}$ content, and can be expressed as:

$$
\begin{aligned}
\Delta S_{f}= & 9.12565-1.07759 C+0.16992 C^{2}-1.003 \times 10^{-2} C^{3} \\
& +2.11749 \times 10^{-4} C^{4} .
\end{aligned}
$$

If Sn content locates between $21 \mathrm{wt} \%$ and $52 \mathrm{wt} \%$, the entropy of fusion increases with the rise of Sn content, and their relationship can be written as:

$$
\Delta S_{f}=7.82743-0.40294 C+0.01926 C^{2}-1.87824 \times 10^{-4} C^{3} .
$$

Once the Sn content is larger than $96.5 \mathrm{wt} \%$,

$$
\Delta S_{f}=-9.61007+1.08715 C-0.01735 C^{2}+8.89497 \times 10^{-5} C^{3} \text {. }
$$

\subsection{Undercoolability of liquid Ag-Sn alloys}

The undercooling $\left(\Delta T=T_{\mathrm{L}}-T_{\mathrm{S} 1}\right)$ of different Ag-Sn alloys obtained in the DSC calorimeter at scan rates of 5 and 40 $\mathrm{K} / \mathrm{min}$ is measured. Here, $T_{\mathrm{S} 1}$ is the initial solidification temperature of a specific Ag-Sn alloy upon cooling. Figure 4(a) illustrates the undercooling distribution at a scan rate of $5 \mathrm{~K} / \mathrm{min}$. The undercooling versus composition can be divided into three regions, which are $0-21 \mathrm{wt} \% \mathrm{Sn}, 21 \mathrm{wt} \%-$
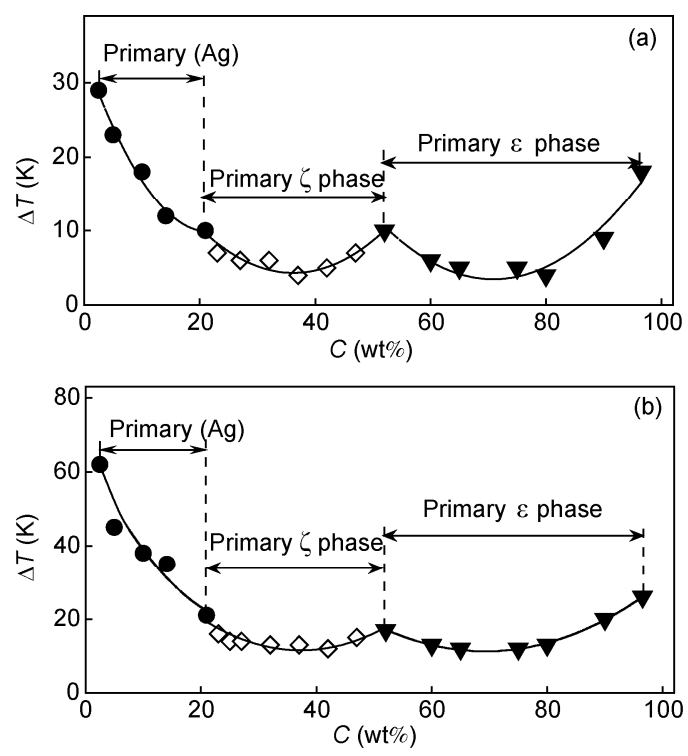

Figure 4 Measured undercoolings of liquid Ag-Sn alloys versus Sn content at different scan rates. (a) $5 \mathrm{~K} / \mathrm{min}$; (b) $40 \mathrm{~K} / \mathrm{min}$. 
$52 \mathrm{wt} \% \mathrm{Sn}$ and $52 \mathrm{wt} \%-96.5 \mathrm{wt} \% \mathrm{Sn}$. In the first region, the $(\mathrm{Ag})$ phase always solidifies primarily in all the alloys, and the undercooling decreases from 29 to $10 \mathrm{~K}$ with the increase of Sn content. Then, the undercooling drops dramatically to about $5-10 \mathrm{~K}$ in the alloys of the second region. As for these alloys, their solidification processes initiate with the nucleation of intermetallic compound $\zeta$ phase. In the third region, where the intermetallic $\varepsilon$ phase nucleates preferentially from all the liquid alloys, the undercooling shows an increasing tendency from about 5 to $18 \mathrm{~K}$ with the increase of Sn content. If the cooling rate goes up to $40 \mathrm{~K} / \mathrm{min}$, as presented in Figure 4(b), the undercooling distribution shows the same changing tendency as that at $5 \mathrm{~K} / \mathrm{min}$. These results suggest that the undercoolability achieved in the DSC experiments is strongly dependent on the primarily nucleating solid phases and follows the relationship below:

$$
\Delta T_{(\mathrm{Ag})}>\Delta T_{\varepsilon}>\Delta T_{\zeta} .
$$

The undercoolability of those liquid alloys solidifying with primary $(\mathrm{Ag})$ solid solution phase is stronger than the other alloys with the preferential nucleation of intermetallic compounds $\zeta$ and $\varepsilon$ phases. Furthermore, it also needs to be mentioned that the undercooling level of all these alloys rises accordingly with the increase of cooling rate from 5 to $40 \mathrm{~K} / \mathrm{min}$. This indicates that faster cooling rate facilitates the higher undercooling of liquid Ag-Sn alloys.
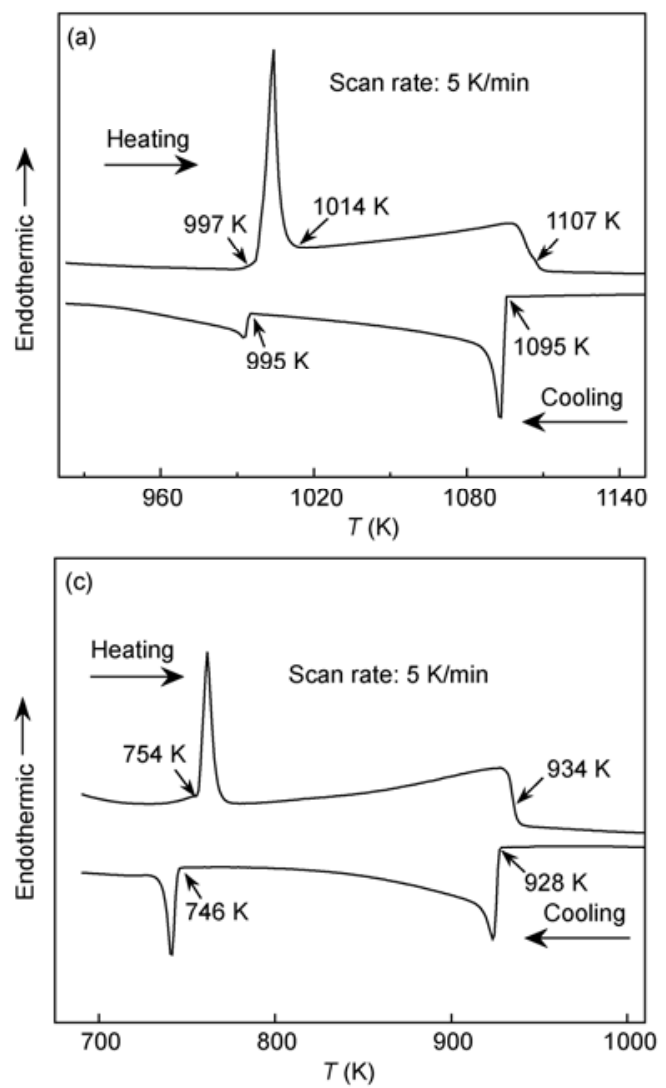

\subsection{DSC curves and microstructural features}

In order to present a comprehensive survey on the phase transition characteristics, the DSC curves and growth morphologies for different types of Ag-Sn alloys are analyzed. Figure 5(a) and (b) show the DSC curves and solidified microstructure of peritectic $\mathrm{Ag}-14.12 \mathrm{wt} \% \mathrm{Sn}$ alloy. There are two endothermic events during its melting process. The first endothermic peak corresponds to the decomposition of solid peritectic $\zeta$ phase into liquid and $(\mathrm{Ag})$ phases, while the second one relates to the melting of $(\mathrm{Ag})$ phase. The peritectic and liquidus temperatures of this alloy are 997 and $1107 \mathrm{~K}$, respectively. During the cooling process, the primary $(\mathrm{Ag})$ phase nucleates at $1095 \mathrm{~K}$ with a very sharp crystallization peak, and the following peritectic transition $\mathrm{L}+(\mathrm{Ag}) \rightarrow \zeta$ at $995 \mathrm{~K}$ yields another relatively broad exothermal peak. As shown in Figure 5(b), the solidified microstructure consists of both the primary (Ag) dendrites and the peritectic $\zeta$ phase, whose volume fractions are about $30 \%$ and $70 \%$, respectively. In fact, under equilibrium condition, $100 \% \zeta$ phase is expected to be obtained at the end of solidification process. However, since the peritectic transformation is mainly controlled by atomic interdiffusion and it is very slow, the peritectic reaction can only occur to a limited extent even under slow cooling condition during the DSC experiments. Consequently, the microstructure is
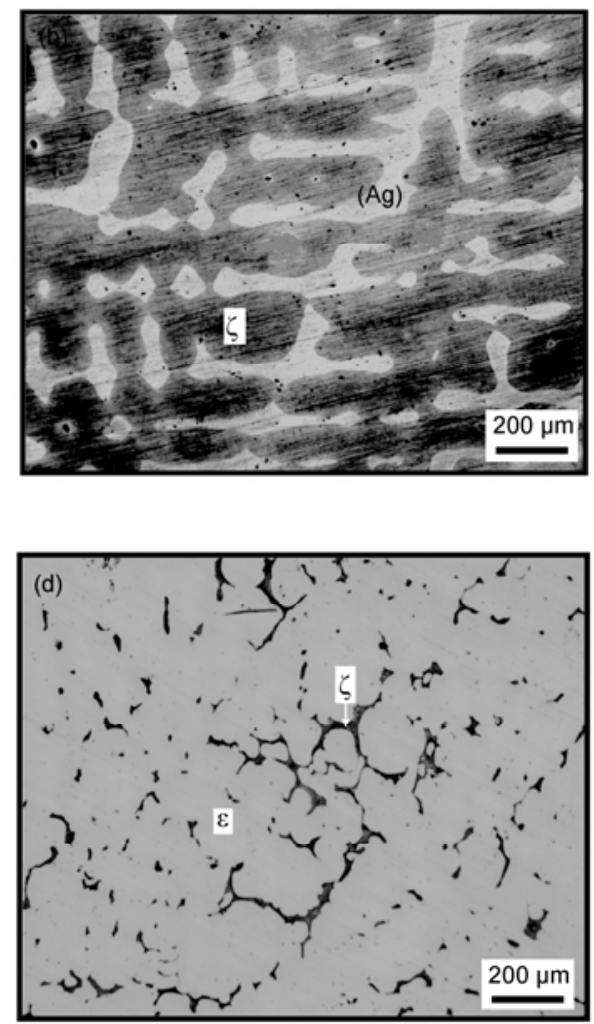

Figure 5 Thermal and structural analyses of two peritectic Ag-Sn alloys. (a) DSC curves of Ag-14.12wt\%Sn alloy; (b) microstructure of Ag-14.12wt\%Sn alloy; (c)DSC curves of Ag-27wt\% Sn alloy and (d) microstructure of Ag-27wt\%Sn alloy. 
composed of peritectic $\zeta$ phase and primarily precipitated (Ag) phase.

The DSC profiles of peritectic Ag-27wt\% $\mathrm{Sn}$ alloy are presented in Figure 5(c). There are also two endothermic and two exothermic peaks during heating and cooling processes. The peritectic and liquidus temperatures of this peritectic alloy are 754 and $934 \mathrm{~K}$. During cooling, the first exothermal peak at $928 \mathrm{~K}$ relates to the nucleation and growth of priamry $\zeta$ phase. The second exothermic event at $746 \mathrm{~K}$ corresponds to the peritectic transition $\mathrm{L}+\zeta \rightarrow \varepsilon$. As illustrated in Figure 5(d), the peritectic $\varepsilon$ phase grows into equiaxed grains. It is worthwhile to note that there still remains some primary $\zeta$ dendrites, which distribute at the grain boundaries of peritectic $\varepsilon$ phase. This demonstrates again that the peritectic transformation can hardly be completed even under near-equilibrium condition.

Figure 6(a) depicts the thermographs of Ag-60wt $\% \mathrm{Sn}$ hypoeutectic alloy, whose eutectic and liquidus temperatures are 494 and $726 \mathrm{~K}$, respectively. During the heating process, the melting of $(\varepsilon+\mathrm{Sn})$ eutectic structure yields a sharp endothermic peak whereas that of primary $\varepsilon$ phase produces a very board peak. In the cooling period, the primary $\varepsilon$ phase solidifies preferentially form the liquid alloy at $718 \mathrm{~K}$, and it grows into long faceted plate, as shown in Figure 6(b). This differs with its nonfaceted growth morphology in Ag-27wt\%Sn alloy as the peritectic phase. When the temperature drops to $476 \mathrm{~K}$, eutectic transformation $\mathrm{L} \rightarrow(\varepsilon+\mathrm{Sn})$ occurs. As presented in Figure 6(c), the eutectic structure is characterized by a small of amount of needle shaped $\varepsilon$ phase distributed in the eutectic $(\mathrm{Sn})$ phase matrix. This is because the volume fraction of eutectic ( $\mathrm{Sn}$ ) phase is much higher than that of eutectic $\varepsilon$ phase, and regular lamellar eutectic structure can not form in this case.

\section{Conclusions}

In summary, the liquidus and solidus temperatures and enthalpy of fusion for binary Ag-Sn alloys in the whole composition range are determined by DSC method. The relationship between enthalpy of fusion and Sn content can be fitted by polynomial functions, which show one maximum value around $52 \mathrm{wt} \% \mathrm{Sn}$ and display two minimum values around $21 \mathrm{wt} \% \mathrm{Sn}$ and $96.5 \mathrm{wt} \% \mathrm{Sn}$, respectively. The liquidus slope, the solidification temperature interval, the solute partition coefficient and the entropy of fusion are calculated on the basis of the measured results. The undercoolability of liquid Ag-Sn alloys depends mainly on the primary solid phases, and shows an increasing tendency with the increase of cooling rate. The undercoolings of those liquid alloys solidifying with primary (Ag) solid solution phase are higher than the other alloys with the preferential nucleation of $\zeta$ and $\varepsilon$ intermetallic compounds. The morphological observation reveals that the primary $\varepsilon$ phase in Ag- $60 \mathrm{wt} \% \mathrm{Sn}$
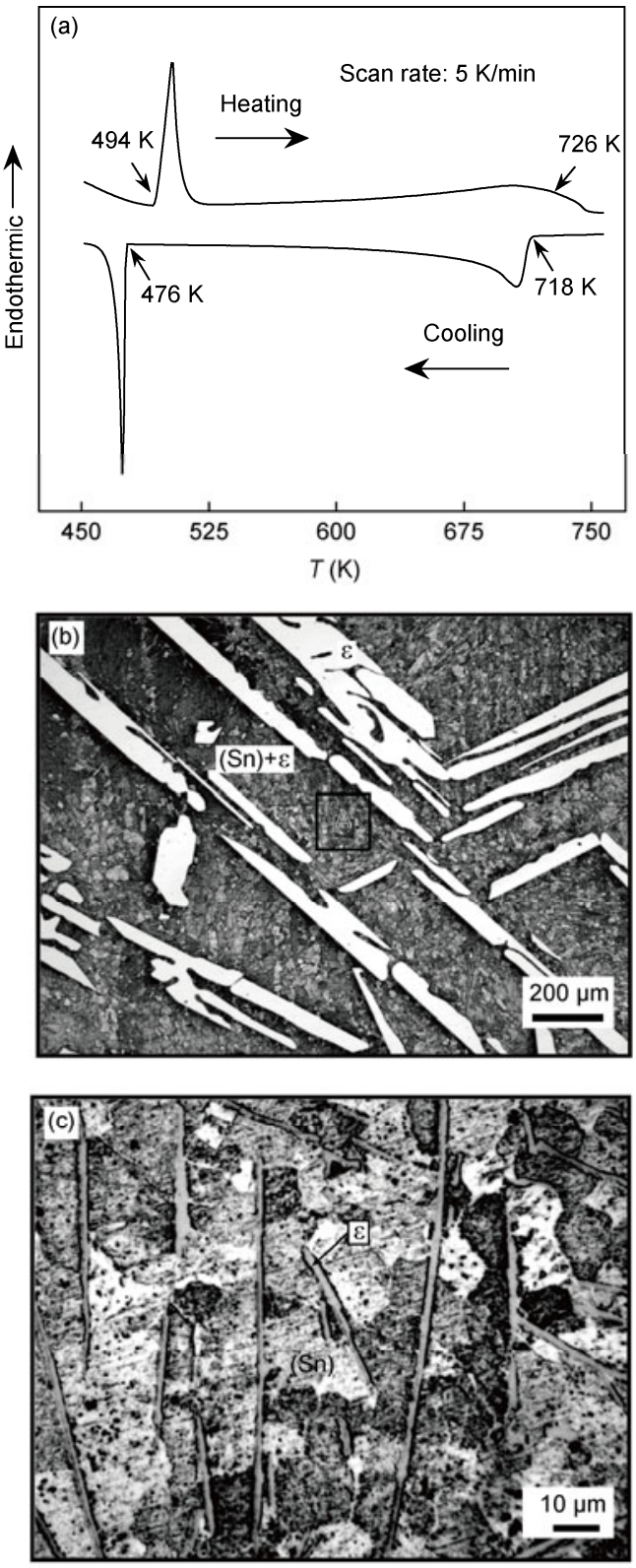

Figure 6 DSC thermograph and microstructures of hypoeutectic Ag-60\%Sn alloy. (a) DSC curves; (b) growth morphology of primary $\varepsilon$ phase; (c) microstructure of $(\mathrm{Sn}+\varepsilon)$ eutectic in Zone A marked in (b).

hypoeutectic alloy grows into faceted plate, and the $(\varepsilon+\mathrm{Sn})$ eutectic structure is characterized by needle shaped $\varepsilon$ phase distributed in the $(\mathrm{Sn})$ matrix. The peritectic reactions can rarely be completed in the $\mathrm{Ag}-14.12 \mathrm{wt} \% \mathrm{Sn}$ and $\mathrm{Ag}-$ $27 \mathrm{wt} \% \mathrm{Sn}$ peritectic alloys, and their solidification microstructures are composed of both primary and peritectic phases.

This work was supported by the National Natural Science Foundation of China (50971105 and 51201136), Doctoral Fund of Ministry of Education of china (20126102120059), Aviation Foundation of China (2012ZF53069), Technology Foundation for Selected Overseas Chinese Scholar, ShaanXi Province, Northwestern Polytechnical University Excellent Personnel 
Supporting Project of Ao Xiang Star, and Fundamental Research Fund of Northwestern Polytechnical University (JC20110280).

1 Yagodin D, Sidorov V, Janickovic D, et al. Density studies of liquid alloys Sn-Ag and Sn-Zn with near eutectic compositions. J Non-cryst Solids, 2012, 358: 2935-2937

2 Chen F X, Pang J H L. Characterization of IMC layer and its effect on thermomechanical fatigue life of $\mathrm{Sn}-3.8 \mathrm{Ag}-0.7 \mathrm{Cu}$ solder joints. $\mathrm{J}$ Alloy Compd, 2012, 541: 6-13

3 Shohji I, Yoshida T, Takahashi T. Tensile properties of Sn-Ag based lead-free solders and strain rate sensitivity. Mater Sci Eng A, 2004, 366: 50-55

4 Phung V S, Fujitsuka A, Ohshima, K I. Influence of 0.03 wt.\% carbon black addition on the performance of $\mathrm{Sn}-3.5 \mathrm{Ag}$ lead-free solder. J Electron Mater, 2012, 41: 1893-1897

5 Garnier T, Finel A, Bouar Y L, et al. Simulation of alloy thermodynamics: From an atomic to a mesoscale Hamiltonian. Phys Rev B, 2012, 86: 054103

6 Terasaki $\mathrm{H}$, Yamagishi $\mathrm{H}$, Moriguchi $\mathrm{K}$, et al. Correlation between the thermodynamic stability of austenite and the shear modulus of polycrystalline steel alloy. J Appl Phys, 2012, 111: 093523

7 Hülsen B, Scheffler M, Kratzer P. Thermodynamics of the Heusler alloy $\mathrm{Co}_{2-x} \mathrm{Mn}_{1+x} \mathrm{Si}$ : A combined density functional theory and cluster expansion study. Phys Rev B, 2009, 79: 094407

8 Ray P K, Chattopadhyay K, Murty B S. Influence of thermodynamics and local geometry on glass formation in $\mathrm{Zr}$ based alloys. Appl Phys Lett, 2008, 93: 061903
9 Wang Z M, Wang J Y, Jeurgens L P H, et al. Thermodynamics and mechanism of metal-induced crystallization in immiscible alloy systems: Experiments and calculations on $\mathrm{Al} / \mathrm{a}-\mathrm{Ge}$ and $\mathrm{Al} / \mathrm{a}-\mathrm{Si}$ bilayers. Phys Rev B, 2008, 77: 045424

10 Kissavos A E, Shallcross S, Kaufman L, et al. Thermodynamics of ordered and disordered phases in the binary Mo-Ru system. Phys Rev B, 2007, 75: 184203

11 Buschbeck J, Fähler S, Weisheit M, et al. Thermodynamics and kinetics during pulsed laser annealing and patterning of FePt films. J Appl Phys, 2006, 100: 123901

12 Harvey J P, Gheribi A E, Chartrand P. On the determination of the glass forming ability of $\mathrm{Al}_{x} \mathrm{Zr}_{1-x}$ alloys using molecular dynamics, Monte Carlo simulations, and classical thermodynamics. J Appl Phys, 2012, 112: 073508

13 Rouxel T. Thermodynamics of viscous flow and elasticity of glass forming liquids in the glass transition range. J Chem Phys, 2011, 135: 184501

14 Curiotto S, Battezzati L, Johnson E, et al. Thermodynamics and mechanism of demixing in undercooled $\mathrm{Cu}-\mathrm{Co}-\mathrm{Ni}$ alloys. Acta Mater, 2007, 55: 6642-6650

15 Moukhina E. Enthalpy calibration for wide DSC peaks. Thermochim Acta, 2011, 522: 96-99

16 Jia R, Bian X F, Wang Y Y. Thermodynamic determination of fragility in La-based glass-forming liquid. Chin Sci Bull, 2011, 56: 3912-3918

17 Karakaya I, Thompson W T. Ag-Sn phase diagram. Bull Alloy Phase Diagrams, 1987, 8: 340-347

Open Access This article is distributed under the terms of the Creative Commons Attribution License which permits any use, distribution, and reproduction in any medium, provided the original author(s) and source are credited. 